\title{
Do natural container habitats impede invader dominance? Predator-mediated coexistence of invasive and native container-dwelling mosquitoes
}

Banugopan Kesavaraju • Kavitha Damal •

Steven A. Juliano

Published online: 16 October 2008

(C) Springer-Verlag 2008

Erratum to: Oecologia (2008) 155:631-639

DOI 10.1007/s00442-007-0935-4

The pooled least squares means for cemeteries in Fig. 1a and $b$ (filled circles) were plotted incorrectly. Those pooled least squares means should be as follows:

All other points in Fig. 1 are plotted correctly.
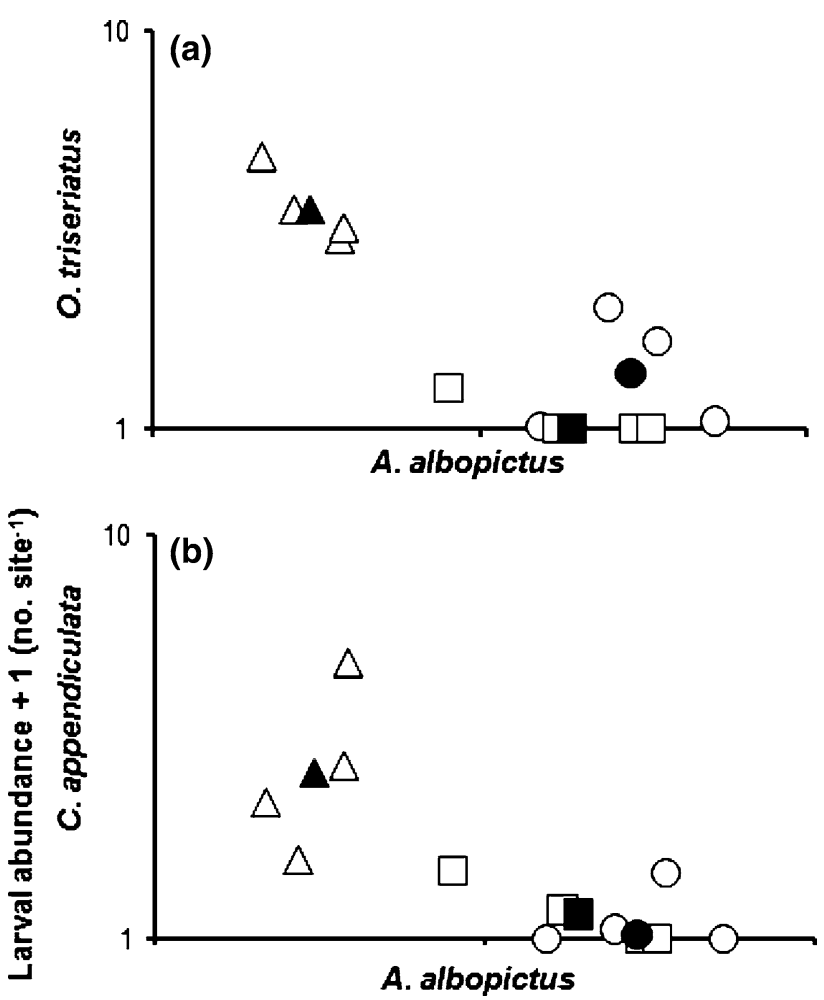

The online version of the original article can be found under doi:10.1007/s00442-007-0935-4.

B. Kesavaraju $(\bowtie) \cdot$ K. Damal · S. A. Juliano

Department of Biology,

Illinois State University, Normal, IL 61790, USA

e-mail: banu@ rci.rutgers.edu

B. Kesavaraju

Center for Vector Biology, Rutgers University,

180 Jones Avenue, New Brunswick, NJ 08901, USA 